\title{
A study on the comparison of minimally invasive surfactant therapy with insure technique of surfactant therapy in preterm babies with respiratory distress in a tertiary care hospital - A prospective cohort study
}

\author{
Andra Akhila ${ }^{1}$, Bhaswati Ghoshal' ${ }^{2}$ Nepal Chandra Mahapatra ${ }^{3}$ \\ From ${ }^{I}$ NICU, ${ }^{2}$ Associate Professor, Department of Pediatric Medicine, ${ }^{3}$ Professor and Head of Department, Department of Pediatrics, Calcutta \\ National Medical College and Hospital, Kolkata, West Bengal, India
}

\begin{abstract}
Background: Respiratory distress syndrome (RDS) is a common problem in preterm babies due to surfactant deficiency. Initially, babies were given surfactant therapy by intubation, surfactant administration, and extubation (INSURE) method. Minimally invasive surfactant therapy (MIST) is a novel method of surfactant administration without intubation to spontaneously breathing preterm babies with RDS without the removal of continuous positive airway pressure (CPAP). Aim: This study aims to compare the surfactant therapy in preterm babies with RDS through MIST and INSURE technique. Methods: This prospective, observational cohort study was conducted in the neonatology unit of Calcutta National Medical College and Hospital. A total of 212 preterm babies of $<37$ weeks of gestation with features of RDS, who require surfactant are taken and divided into two groups. Very sick babies with congenital anomalies are excluded from the study. In MIST group ( $\mathrm{n}=102), 8 \mathrm{Fr}$ feeding tube is used to deliver surfactant while the baby is on CPAP. In INSURE group $(\mathrm{n}=102)$, surfactant is given by intubation through endotracheal tube without CPAP and extubated. Results: Mean birth weight was $1.26 \mathrm{~kg}$ in MIST and $1.22 \mathrm{~kg}$ in INSURE. Mean gestational age was 31.33 weeks in MIST and 31.11 weeks in INSURE. It was observed that there is a significant difference in terms of duration of oxygen requirement, neonatal intensive care unit stay, and surfactant spillage during administration in MIST group compared to INSURE group. However, duration of mechanical ventilation, CPAP, number of doses of surfactant, sepsis, intraventricular hemorrhage, retinopathy of prematurity, pneumothorax, bronchopulmonary dysplasia, and mortality did not show significant difference in both the groups. Conclusion: MIST is safe, feasible, and more beneficial than INSURE technique.
\end{abstract}

Key words: Surfactant, Respiratory distress, Preterm, CPAP, MIST, INSURE

$\mathrm{P}$ reterm babies with respiratory distress syndrome (RDS) need exogenous surfactant as surfactant producing type 2 alveolar pneumocytes begin to develop after the third trimester. Surfactant replacement therapy has proven effective in reducing mortality and pulmonary morbidity $[1,2]$ and has been a mainstay of therapy in preterm infants intubated soon after birth. Recent randomized multicenter trials have shown that the use of continuous positive airway pressure (CPAP) in the delivery room has been at least as effective as intubation and surfactant administration in the $1^{\text {st }}$ minutes after birth with trends toward reduction of mechanical ventilation (MV) and the incidence of bronchopulmonary dysplasia (BPD) [3-5]. Techniques of minimally invasive surfactant therapy (MIST)

\section{Access this article online}

Received - 10 September 2021

Initial Review - 29 September 2021

Accepted - 12 October 2021

DOI: $10.32677 / \mathrm{IJCH} .2021 . v 08.110 .3097$ have recently been investigated, aiming to administer surfactant to spontaneously breathing infants, allowing them to remain on CPAP in the critical $1^{\text {st }}$ days after birth and, hopefully, beyond without intubation. These techniques have included administration of exogenous surfactant by brief tracheal catheterization, pharyngeal instillation, nebulization, and laryngeal mask [6]. Of these, the methods involving brief tracheal catheterization have been most extensively studied, with surfactant administered using both a flexible feeding tube and a semi-rigid vascular catheter. INSURE technique needs intubation, bolus surfactant administration, temporary bag, and tube ventilation after surfactant administration. MIST is gentle, safe, feasible, and effective in preterm infants with non-invasive respiratory support by neonatologists [6]. In this study, we want to compare these two methods of surfactant administration in pre-term babies with RDS.

Correspondence to: Bhaswati Ghoshal, Department of Pediatric Medicine, Calcutta National Medical College and Hospital, Kolkata, West Bengal, India.

E-mail: bhaswatighoshalmailme@yahoo.com

(C) 2021 Creative Commons Attribution-NonCommercial 4.0 International License (CC BY-NC-ND 4.0). 


\section{METHODS}

This is a prospective, observational cohort study carried out at the neonatology unit in Calcutta National Medical College and Hospital for a period of 1 year from June 2019 to June 2020 in preterm babies with RDS. Surfactant is given as per European Consensus Guidelines 2019 on RDS [7]. Extremely sick babies with congenital anomalies are excluded from the study. After obtaining ethical clearance, informed consent is taken from the parents in their own language. As the baby is received in sick newborn care unit, Silverman-Anderson scoring (SAS) [8] for RDS is done. If SAS $>5$, then the baby is put on nasal CPAP. Preterm neonates with RDS requiring surfactant therapy are divided into MIST group and INSURE group randomly. In preterm babies with RDS if $\mathrm{FiO} 2>30 \%$ on CPAP then according to European Consensus Guidelines 2019 on RDS [7], surfactant usually poractant alfa $(200 \mathrm{mg} / \mathrm{kg})$ of phospholipid given by either MIST or INSURE technique.

In MIST, the baby will be on CPAP with initial settings started with $5 \mathrm{~cm}$ of $\mathrm{H}_{2} \mathrm{O}$ and $\mathrm{FiO}_{2}$ adjusted to achieve target saturation of $90-95 \%$ using a bubble CPAP or ventilator CPAP based on availability using nasal mask as interface. Heart rate and oxygen saturation $\left(\mathrm{SpO}_{2}\right)$ were monitored throughout the procedure. Required quantity of surfactant was taken into syringe and an additional $1 \mathrm{ml}$ of air drawn into syringe taking account for the dead volume of the catheter used. Eight Fr feeding tube to be cut in sterile manner depending on length of endotracheal tube with nozzle end to be taken for surfactant administration and surfactant was given slowly over 2 min with syringe fitted with nozzle in a single bolus by direct laryngoscopy. After surfactant therapy, feeding tube was removed after pushing $1 \mathrm{ml}$ of air for the surfactant to enter completely. The baby will be on nasal CPAP during the entire procedure. If the baby did not respond to the procedure or has $\mathrm{FiO} 2>30 \%$ even after $6 \mathrm{~h}$ of giving surfactant, then second dose of surfactant was considered. The maximum upper limit for CPAP was $7 \mathrm{~cm}$ of $\mathrm{H}_{2} \mathrm{O}$ and $\mathrm{FiO}_{2}$ of $70 \%$. Infants not maintaining saturation on these settings were intubated.

In INSURE technique, the baby is removed from CPAP. Endotracheal tube was inserted using laryngoscope for surfactant therapy. Five Fr feeding tube was taken and cut according to the length of the endotracheal tube. Surfactant is instilled in 2-3 boluses through the feeding tube in the endotracheal tube into the trachea followed by continuation of the bag and tube ventilation for $2-3 \mathrm{~min}$. The baby is then extubated and put on CPAP.

Main outcome parameters, compared between MIST and INSURE group of neonates, include number of doses of surfactant therapy, duration of CPAP, surfactant spillage during administration, duration of oxygen requirement, duration of MV, duration of neonatal intensive care unit (NICU) stay, and mortality. Statistical analysis was performed using IBM SPSS Statistics 22 software for Windows. Independent samples t-test was performed for continuous variables and they were expressed as means \pm standard deviation. Chi-square test (or Fisher's exact test) was performed for categorical data. $\mathrm{p}<0.05$ was considered as statistically significant.

The sample size calculation was done by comparing the means of INSURE group and MIST group regarding primary outcome of our study. To have power of the study as $80 \%$ and significance level of $5 \%$ and using the standard deviation value of pilot study done before the main study and expecting an effect size of approximately 2 days difference in the duration of oxygen requirement, sample size calculated was 54 in each group. The current study, however, included 106 newborns in each group.

\section{RESULTS}

The baseline characteristics of the neonates included in our study are summarized in Table 1 which showed no significant difference in the MIST and INSURE groups.

The outcome variables are summarized in Table 2, showing significant difference between the MIST and INSURE groups in terms of surfactant spillage, duration of oxygen requirement, and NICU stay.

\section{DISCUSSION}

Several cases of RDS in preterm babies are now treated with nasal CPAP soon after birth. Surfactant replacement has become one of the common modalities which have improved the survival of preterm infant. MIST allows for surfactant administration while the baby is on CPAP, requiring no intubation and bagging. This can decrease lung injury and infection. In the neonatology unit of $\mathrm{CNMCH}$, every year approximately 1900 (both inborn and outborn) admissions occur of which, nearly $41.3 \%$ are preterm admissions. As there is free supply of surfactant available, we wanted to compare MIST with INSURE technique of surfactant administration in preterm babies with RDS.

In our study, mean duration of oxygen requirement was significantly reduced in the MIST group compared to the INSURE group $(\mathrm{p}<0.002)$ (Fig. 1). Similar observation was reported by Jena et al. [9] who reported that the duration of oxygen was 6 days in MIST and 12 days in INSURE, which was a significant reduction $(p<0.01)$. Significant difference was also reported in the study by Dargaville et al. [10]. In Accuitive Medical Ventures (AMV) [11], infants in the MIST group had lower need for oxygen therapy at 28 days compared to the INSURE group. This might be due to lung injury caused by few mechanical breaths in the INSURE group. End expiratory lung volume is improved after MIST and is associated with oxygenation improvement [12].

The mean duration of NICU stay was significantly less in the MIST group compared to the INSURE group $(\mathrm{p}=0.017)$ in our study (Fig. 2). In a study by Jena et al. [9], NICU stay was 11 days in the MIST group and 28 days in the INSURE group showing significant reduction in the MIST group $(p<0.01)$ which corroborates with our study. This might be due to less oxygen requirement and less lung injury in the MIST group. 
Table 1: Baseline characteristics of MIST and INSURE technique for surfactant administration

\begin{tabular}{|c|c|c|c|}
\hline Baseline characteristics & MIST & INSURE & p-value \\
\hline Mean gestational age (weeks) (Mean \pm SD) & $31.33 \pm 2.899$ & $31.11 \pm 2.87$ & 0.203 \\
\hline LSCS & $38(37.3 \%)$ & $41(40.2 \%)$ & 0.47 \\
\hline Mean birth weight $(\mathrm{kg})($ Mean \pm SD) & $1.26 \pm 0.31$ & $1.22 \pm 0.30$ & 0.236 \\
\hline Boy & $53(52 \%)$ & $54(52.9 \%)$ & 0.07 \\
\hline Multiple births & $12(11.7 \%)$ & $20(19.6 \%)$ & 0.18 \\
\hline SGA babies & $31(30.3 \%)$ & $32(31.3 \%)$ & 0.19 \\
\hline $1^{\text {st }}$ dose surfactant within $2 \mathrm{~h}$ of birth & $58(56.8 \%)$ & $56(54.9 \%)$ & 0.24 \\
\hline Complete dose of antenatal steroids & $45(44.1 \%)$ & $47(46 \%)$ & 0.28 \\
\hline
\end{tabular}

MIST: Minimally invasive surfactant therapy, INSURE: Intubation, surfactant administration, and extubation, SD: Standard deviation, LSCS: Lower segment cesarean section, SGA: Small for gestational age

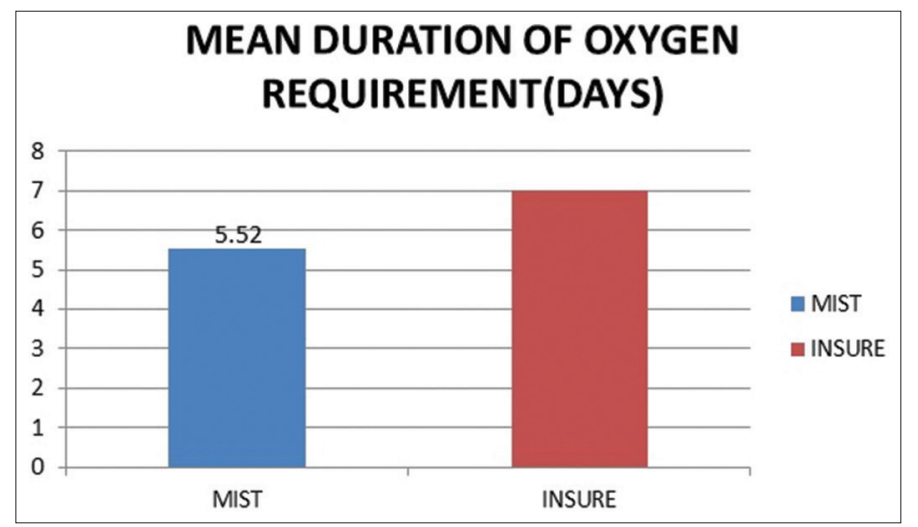

Figure 1: Mean duration of oxygen requirement in minimally invasive surfactant therapy and intubation, surfactant administration, and extubation technique of surfactant administration

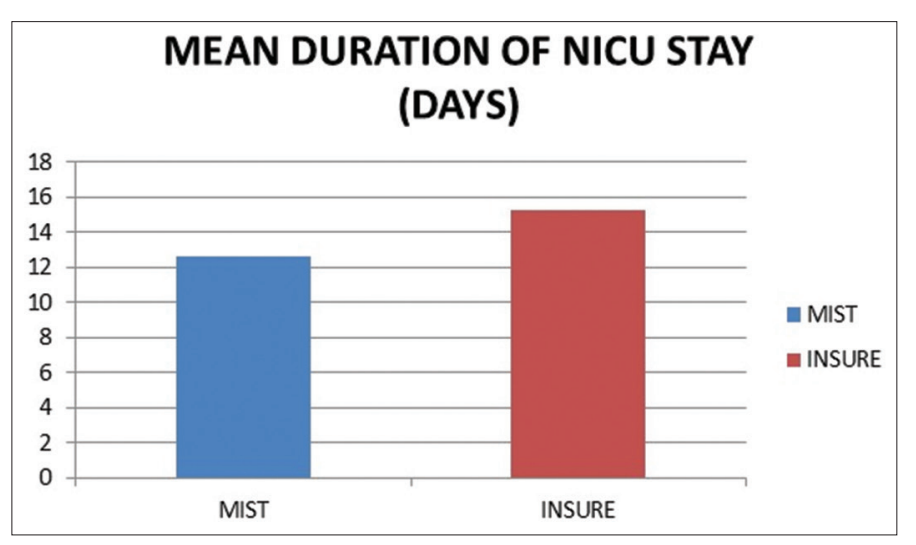

Figure 2: Mean duration of neonatal intensive care unit stay in minimally invasive surfactant therapy and intubation, surfactant administration, and extubation technique of surfactant administration

Spillage during surfactant therapy was also significantly reduced in the MIST group compared to the INSURE group in the current study. Dargaville et al. reported that one-third of preterm infants (25-28 weeks of gestation) developed this complication on using the MIST technique [10]. Cologne method involves, closing the mouth during surfactant administration which has helped to reduce the surfactant spillage [13]. Furthermore, using a lower volume surfactant formula, Curosurf would be another option to decrease surfactant spillage.
Mortality showed no significant difference in both the groups as was also in evidence in AMV [11] trial. Aldana-Aguirre et al. [14] in another recent meta-analysis with a total of $895 \mathrm{infant}$ observed reduction in mortality $(\mathrm{p}=0.01)$ in the MIST group. Jena et al. [9] reported that there was no difference in mortality between the two groups. In a recent study done in Taiwan, the MIST group was found to have significantly lower rate $(\mathrm{p}<0.05)$ of mortality [15].

It was also observed that there were no differences seen in both the groups in terms of sepsis, ROP, BPD, pneumothorax, and IVH in our study. Although the risk of BPD appears to be lower in infants over 28 weeks of gestation, it should be noted that, in more-preterm infants, the need for intubation and even brief positive pressure ventilation by bagging for surfactant administration could be more damaging when using the INSURE method than with the MIST method. On the other hand, spontaneous breathing during the MIST technique is believed to spread surfactant more uniformly causing less lung injury [9]. The incidence of BPD could thus be reduced. In a study by Jena et al. [9], significant reduction in BPD was observed in the MIST group with no significant difference in terms of sepsis and IVH. In a recent Taiwan-based study, the MIST group had significantly lower rate $(p<0.05)$ of composite outcome of BPD [15].

Regarding requirement of the second dose of surfactant, we found no difference between the two groups. In a study by Kanmaz et al. [16], an almost equal percentage of both groups (about 20\%) required the second dose of surfactant which is in accord to our observation. Studies by Jena et al. [9] and AldanaAguirre et al. [14] also reported no difference in the $2^{\text {nd }}$ dose of surfactant in both the groups. In the study by Aguar et al. [17], the infants in the MIST group received a $100 \mathrm{mg} / \mathrm{kg}$ dose of Curosurf and those in the INSURE group received a $200 \mathrm{mg} / \mathrm{kg}$ dose, and about $36 \%$ of the MIST group and only $6.5 \%$ of the INSURE group needed the second dose of surfactant. From these, it was observed that initial dose of surfactant appears to dictate the need for a second administration of surfactant regardless of the technique used.

The mean duration of CPAP showed no statistically significant difference in both the groups in the current study. Jena et al. [9], however, showed that the mean duration of CPAP was 4 in MIST and 8 in the INSURE group, having significant reduction in the 
Table 2: Outcome variables comparing MIST with INSURE technique of surfactant administration

\begin{tabular}{|c|c|c|c|}
\hline Outcome variables & MIST & INSURE & p-value \\
\hline $2^{\text {nd }}$ dose of surfactant & $10(9.8 \%)$ & $10(9.8 \%)$ & 0.258 \\
\hline Mean duration of CPAP (days) (Mean \pm SD) & $2.27 \pm 1.415$ & $2.5 \pm 1.510$ & 0.924 \\
\hline Surfactant spillage & $13(12.7 \%)$ & $21(20.5 \%)$ & $<0.01$ \\
\hline Mean duration of oxygen requirement (days) $($ Mean \pm SD) & $5.52 \pm 3.665$ & $7.06 \pm 4.82$ & 0.002 \\
\hline Mean duration of MV (days) (Mean \pm SD) & $0.46 \pm 0.972$ & $0.81 \pm 1.494$ & 0.746 \\
\hline Mean duration of NICU stay (days) (Mean \pm SD) & $12.59 \pm 7.801$ & $15.25 \pm 9.613$ & 0.017 \\
\hline Mortality & $19.6 \%$ & $20.5 \%$ & 0.64 \\
\hline Sepsis & $17(16.7 \%)$ & $17(16.7 \%)$ & 0.55 \\
\hline ROP & $1(0.98 \%)$ & $1(0.98 \%)$ & 1 \\
\hline IVH & $2(2 \%)$ & $2(2 \%)$ & 0.806 \\
\hline BPD & 0 & $1(1 \%)$ & 0.32 \\
\hline Pneumothorax & $1(1 \%)$ & 0 & 0.32 \\
\hline
\end{tabular}

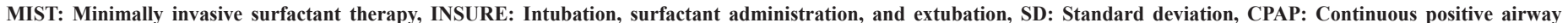
pressure, NICU: Neonatal intensive care unit, ROP: Retinopathy of prematurity, IVH: Intraventricular hemorrhage, BPD: Bronchopulmonary dysplasia

MIST group compared to the INSURE. In the take care trial [18], a significantly shorter duration of CPAP was observed in the MIST group compared to the INSURE group.

Required ventilation in the two groups showed no statistically significant difference in our study, whereas Jena et al. [9] observed a significant reduction in the need for MV in the MIST group (MIST: 19\%, INSURE: 40\%, $\mathrm{p}<0.01$, risk ratio=0.49). In Hobart method [19], there was a significant reduction in the need for intubation at $<72 \mathrm{~h}$ for infants between 25 and 28 weeks' gestation ( $32 \%$ vs. $68 \%$; p $1 / 40.0011)$, with a similar trend in those at 29-32 weeks' gestation ( $22 \%$ vs. $45 \%$; p 1/4 0.057) in the MIST group. Duration of ventilation was similar in both cohorts. Studies by Kanmaz et al. [16] and Aldana-Aguirre et al. [14] observed decrease in MV in the MIST group. In AMV trial [11], a significant reduction in duration of ventilation after birth in the intervention (MIST) group compared to the standard group (INSURE) $(28 \%$ vs. $\left.46 \% ; p^{1 / 4} 0.008\right)$ was observed. Moreover, fewer infants in the intervention group needed $\mathrm{MV}$ at any time compared to infants in the standard group (33\% vs. $73 \%$; $<0.0001)$. In a Taiwanbased recent study [15], the duration of intubation and MV was significantly shorter $(\mathrm{p}<0.001)$ in the MIST group than in the intubated group. The study by Seo et al. in Korea showed that the need for MV was reduced in MIST [20] whereas the study by De Luca and de Winter [21] demonstrates that there was no significant difference in duration of MV in both the groups.

\section{CONCLUSION}

Taken together, significant difference in terms of duration of oxygen requirement, NICU stay, and surfactant spillage was observed in the MIST group compared to the INSURE group. Hence, MIST can be a safe and preferable method of surfactant administration in neonates.

\section{REFERENCES}

1. Guttentag S, Foster CD. Update in surfactant therapy. Neoreviews 2011;12:e625-34.
2. Seger N, Soll R. Animal derived surfactant extract for treatment of respiratory distress syndrome. Cochrane Database Syst Rev 2009;2:CD007836.

3. Morley C, Davis P, Doyle L, Brion L, Hascoet J, Carlin J. Nasal CPAP or intubation at birth for very preterm infants. N Engl J Med 2008;358:700-8.

4. Finer NN, Carlo WA, Walsh MC, Rich W, Gantz MG, Laptook AR, et al. Early CPAP versus surfactant in extremely preterm infants. N Engl J Med 2010;362:1970-9.

5. Dunn MS, Kaempf J, de Klerk A, de Klerk R, Reilly M, Howard D, et al. Randomized trial comparing 3 approaches to the initial respiratory management of preterm neonates. Pediatrics 2011;128:e1069-76.

6. Shim GH. Update of minimally invasive surfactant therapy. Korean J Pediatr 2017;60:273-81.

7. Sweet DG, Carnielli V, Greisen G, Hallman M, Ozek E, Te Pas A, et al. European consensus guidelines on the management of respiratory distress syndrome-2019 update. Neonatology 2019;115:432-50.

8. Silverman WA, Andersen DH. A controlled clinical trial of effects of water mist on obstructive respiratory signs, death rate and necropsy findings among premature infants. Pediatrics 1956;17:1-10.

9. Jena SR, Bains HS, Pandita A, Verma A, Gupta V, Kallem VR, et al. Surfactant therapy in premature babies: SurE or InSurE. Pediatr Pulmonol 2019;54:1747-52.

10. Dargaville PA, Aiyappan A, Cornelius A, Williams C, De Paoli AG. Preliminary evaluation of a new technique of minimally invasive surfactant therapy. Arch Dis Child Fetal Neonatal Ed 2011;96:F243-8.

11. Göpel W, Kribs A, Ziegler A, Laux R, Hoehn T, Weig C, et al. Avoidance of mechanical ventilation by surfactant treatment of spontaneously breathing preterm infants (AMV): An open-label, randomised, controlled trial. Lancet 2011;378:1627-34

12. Kribs A, Vierzig A, Hünseler C, Eifinger F, Welzing L, Stutzer H, et al. Early surfactant in spontaneously breathing with nCPAP in ELBW infants-a single centre four year experience. Acta Paediatr 2008;97:293-8.

13. Kribs A, Pillekamp F, Hünseler C, Vierzig A, Roth B. Early administration of surfactant in spontaneous breathing with nCPAP: Feasibility and outcome in extremely premature infants(postmenstrual age $\leq 27$ weeks). Paediatr Anaesth 2007;17:364-9.

14. Aldana-Aguirre JC, Pinto M, Featherstone RM, Kumar M. Less invasive surfactant administration versus intubation for surfactant delivery in preterm infants with respiratory distress syndrome: A systematic review and meta analysis. Arch Dis Child Fetal Neonatal Ed 2017;102:F17-23.

15. Wang XA, Chen LJ, Chen SM, Su PH, Chen JY. Minimally invasive surfactant therapy versus intubation for surfactant administration in very low birth weight infants with respiratory distress syndrome. Pediatr Neonatol 2020;61:210-5

16. Kanmaz HG, Erdeve O, Canpolat FE, Mutlu B, Dilmen U. Surfactant administration via thin catheter during spontaneous breathing: Randomized controlled trial. Pediatrics 2013;131:502-9.

17. Aguar M, Cernada M, Brugada M, Gimeno A, Gutierrez A, Vento M. 
Minimally invasive surfactant therapy with a gastric tube is as effective as the intubation, surfactant and extubation technique in preterm babies. Acta Paediatr 2014;103:e229-33.

18. Speer CP, Sweet DG, Halliday HL. Surfactant therapy: Past, present and future. Early Hum Dev 2013;89:S22-4.

19. Klebermass-Schrehof K, Wald M, Schwindt J, Grill A, Prusa AR, Haiden N, et al. Less invasive surfactant administration in extremely preterm infants: Impact on mortality and morbidity. Neonatology 2013;103:252-8.

20. Seo MY, Shim GH, Chey MJ. Clinical outcomes of minimally invasive surfactant therapy via tracheal catheterization in neonates with a gestational age of 30 weeks or more diagnosed with respiratory distress syndrome. Neonatal Med 2018;25:109-17.
21. De Luca D, de Winter J. Less invasive surfactant administration: All that glitters is not gold. Eur J Pediatr 2020;179:1295-6.

Funding: Nil; Conflicts of interest: Nil.

How to cite this article: Akhila A, Ghoshal B, Mahapatra NC. A study on the comparison of minimally invasive surfactant therapy with insure technique of surfactant therapy in preterm babies with respiratory distress in a tertiary care hospital - A prospective cohort study. Indian J Child Health. 2021; 8(10):362-366. 